\title{
Electrochemical stability of subnanometer Pt clusters
}

Quinson, Jonathan; Röefzaad, Melanie; Deiana, Davide; Hansen, Thomas W.; Wagner, Jakob Birkedal; Nesselberger, Markus; Crampton, Andrew S.; Ridge, Claron J.; Schweinberger, Florian F.; Heiz, Ueli Total number of authors:

11

Published in:

Electrochimica Acta

Link to article, DOI:

10.1016/j.electacta.2018.04.211

Publication date:

2018

Document Version

Peer reviewed version

Link back to DTU Orbit

Citation (APA):

Quinson, J., Röefzaad, M., Deiana, D., Hansen, T. W., Wagner, J. B., Nesselberger, M., Crampton, A. S., Ridge, C. J., Schweinberger, F. F., Heiz, Ü., \& Arenz, M. (2018). Electrochemical stability of subnanometer Pt clusters. Electrochimica Acta, 277, 211-217. https://doi.org/10.1016/j.electacta.2018.04.211

\section{General rights}

Copyright and moral rights for the publications made accessible in the public portal are retained by the authors and/or other copyright owners and it is a condition of accessing publications that users recognise and abide by the legal requirements associated with these rights.

- Users may download and print one copy of any publication from the public portal for the purpose of private study or research.

- You may not further distribute the material or use it for any profit-making activity or commercial gain

- You may freely distribute the URL identifying the publication in the public portal 


\section{Accepted Manuscript}

Electrochemical stability of subnanometer Pt clusters

Jonathan Quinson, Melanie Röefzaad, Davide Deiana, Thomas W. Hansen, Jakob B. Wagner, Markus Nesselberger, Andrew S. Crampton, Claron J. Ridge, Florian F. Schweinberger, Ueli Heiz, Matthias Arenz

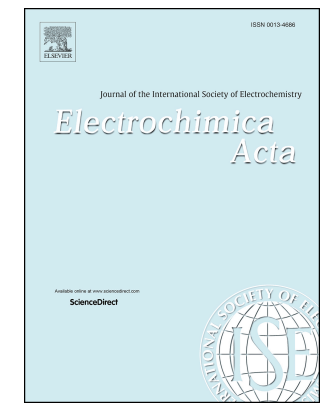

PII:

S0013-4686(18)30996-4

DOI:

10.1016/j.electacta.2018.04.211

Reference: $\quad$ EA 31778

To appear in: Electrochimica Acta

Received Date: 25 March 2018

Revised Date: 27 April 2018

Accepted Date: 27 April 2018

Please cite this article as: J. Quinson, M. Röefzaad, D. Deiana, T.W. Hansen, J.B. Wagner, M. Nesselberger, A.S. Crampton, C.J. Ridge, F.F. Schweinberger, U. Heiz, M. Arenz, Electrochemical stability of subnanometer Pt clusters, Electrochimica Acta (2018), doi: 10.1016/j.electacta.2018.04.211.

This is a PDF file of an unedited manuscript that has been accepted for publication. As a service to our customers we are providing this early version of the manuscript. The manuscript will undergo copyediting, typesetting, and review of the resulting proof before it is published in its final form. Please note that during the production process errors may be discovered which could affect the content, and all legal disclaimers that apply to the journal pertain. 


\section{Electrochemical Stability of Subnanometer Pt}

\section{Clusters}

Jonathan Quinson, ${ }^{\dagger, \ddagger}$ Melanie Röefzaad, ${ }^{\dagger, \ddagger}$ Davide Deiana, ${ }^{\ddagger}$ Thomas W. Hansen, ${ }^{\ddagger}$

4 Jakob B. Wagner, ${ }^{\ddagger}$ Markus Nesselberger, ${ }^{\dagger}$ Andrew S. Crampton, ${ }^{\vdash}$ Claron J. Ridge, ${ }^{\vdash}$ Florian F. 5 Schweinberger, ${ }^{\vdash, \square}$ Ueli Heiz ${ }^{\vdash}$ and Matthias Arenz $z^{\dagger} \aleph^{* *}$

$6{ }^{\dagger}$ Nano-Science Center, Department of Chemistry, University of Copenhagen, Universitetsparken 7 5, DK-2100 Copenhagen $\varnothing$, Denmark

$8 \quad{ }^{\neq}$Technical University of Denmark, Center for Electron Nanoscopy, 2800 Kongens Lyngby

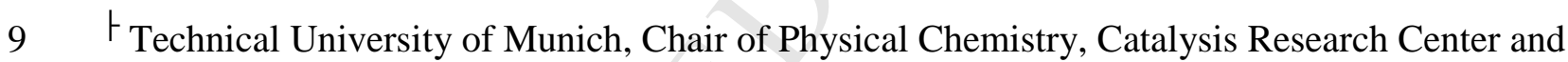
10 Chemistry Department, Ernst-Otto-Fischer-Straße 1 and Lichtenbergstraße 4, 85748 Garching, Germany

※Department of Chemistry and Biochemistry, University of Bern, Freiestrasse 3, CH-3012 Bern, Switzerland 
18

19

*E-mail: matthias.arenz@dcb.unibe.ch

\section{Corresponding Author}

20

21

\section{Present Addresses}

$\square$ F.F.S. Current affiliation: Roche Diagnostics GmbH, Centralized and Point of Care Solutions, DXRESI7F6164, Staffelseestrasse 2-8, 81477 Munich, Germany

\section{Author Contributions}

The manuscript was written through contributions of all authors. All authors have given approval to the final version of the manuscript. $\ddagger$ These authors contributed equally.

8

9

0

1

2

3


40

41

42

In the present work, the degradation of size-selected Pt nanoclusters is studied under electrochemical conditions. This model catalyst mimics carbon supported Pt nanoclusters and nanoparticles typically employed in proton exchange membrane fuel cells (PEMFCs). Insight into the early stage of degradation is given by high-angle annular dark-field scanning transmission electron microscopy (HAADF-STEM) and confirmed by transmission electron microscopy (TEM). In contrast to common assumptions, it is demonstrated that even extremely small Pt clusters exhibit a remarkable stability under electrochemical conditions. Such nanoclusters are then relevant to develop electrodes for energy applications. Furthermore, applying mixed cluster samples of $\mathrm{Pt}_{22}$ and $\mathrm{Pt}_{68}$, no preferential dissolution of $\mathrm{Pt}_{22}$ by Ostwald ripening - usually held responsible to be the main mechanism for activity loss in Pt fuel cell catalysts - is observed. In light of the findings reported, developing highly-dispersed subnanometer Pt clusters as catalyst for PEMFCs is a realistic approach provided the operation conditions are suitably adjusted. Furthermore, mitigation strategies to improve the stability of few-atoms catalyst under electrochemical operation will benefit from addressing cluster-support interactions.

\section{KEYWORDS}

size-selected nanoclusters, stability, platinum, HAADF-STEM 
Catalyst degradation is one of the most important fundamental challenges in catalysis.

62 Commercial applications, such as proton exchange membrane fuel cells (PEMFCs), typically require lifetimes of up to several years [1] and any potential business model needs a fair knowledge of how long a catalyst can sustain a certain degree of performance. In catalyst research and development, however, it is impractical to test every promising catalyst for extended periods of time. Therefore, accelerated degradation tests (ADTs) are applied [2]. On the one hand, these should significantly reduce the degradation time and on the other hand apply conditions as relevant as possible. Also from a fundamental point of view, it is important to understand how the different degradation mechanisms contribute to a performance loss and how these individual contributions depend on the experimental conditions. Such knowledge is essential to develop suitable mitigation strategies to avoid or minimize degradation and/or to define suitable operation conditions for specific catalysts.

In the presented work, we study the electrochemical degradation mechanism [3] of sizeselected Pt nanoclusters [4] deposited onto planar carbon films. Pt nanoclusters and nanoparticles supported on carbon are typically employed in PEMFCs giving the presented results direct relevance for industrial sectors such as automotive and stationary applications. High power density is especially essential [5] for automotive applications, which leads to the need for highly dispersed catalysts to prevent the reaction to become mass transport limited under such conditions [6]. Commonly, high dispersion is achieved by very small Pt or Pt-alloy catalyst particles, which however are prone to instability. It is often assumed that small Pt clusters readily dissolve under electrochemical conditions [7] and thus are unsuitable for electrochemical applications. Here we present experimental evidence that subnanometer Pt clusters are more 
stable than expected and mitigation strategies would benefit from addressing particle detachment, governed by support oxidation and particle - support interaction.

\section{EXPERIMENTAL SECTION}

Cluster preparation: The size-selected Pt nanoclusters were prepared under vacuum conditions by focusing the second harmonic of a $100 \mathrm{~Hz} \mathrm{Nd}$ :YAG $(70 \mathrm{~mJ}$ at $532 \mathrm{~nm}$; InnoLas DPSS Spitlight, Germany) laser along with a delayed pulse of compressed $\mathrm{He}(\mathrm{He}$ 6.0, Westfalen, Germany) onto a rotating platinum disk (99.99\% Pt, Goodfellow, U.S.A.) [8]. The generated neutral and charged Pt clusters of various sizes were cooled via supersonic expansion and the $\mathrm{He}$ pulse and expanded into a differentially pumped vacuum system. The cluster beam was guided by electrostatic ion optics and after passing a electrostatic bender stage the cluster cations were size selected by means of a quadrupole mass-spectrometer (QMS; Extrel, Pittsburgh, U.S.A. mass limit $16000 \mathrm{amu}$ ) [9] down to a single cluster size with precise knowledge of the number of atoms in the cluster. After passing the QMS, the cluster beam was deposited onto holey carbon gold TEM grids covered with a $2 \mathrm{~nm}$ thin amorphous carbon film (Quantifoil, Germany) under soft landing conditions mounted on a sample holder of a manipulator that was connected to a pico-ampere meter (Keithley, USA) [10]. The cluster coverage was calculated from the integration of the neutralization current over time assuming singly charged clusters.

Electrochemistry: For the electrochemical investigations, the gold TEM grids were used as working electrode (WE) of a three-electrode configuration placed in a three-compartment electrochemical Teflon cell. All measurements were performed at room temperature using an inhouse designed potentiostat for potential control. A saturated Calomel electrode served as reference electrode (RE) and a carbon rod as counter electrode (CE). The RE was placed in a 
separate compartment to avoid chloride contaminations. All potentials in this study are given with respect to the reversible hydrogen potential (RHE), which was established experimentally using a Pt disk electrode. $0.1 \mathrm{M} \mathrm{HClO}_{4}$ made from MilliQ-water (> $18 \mathrm{M} \Omega \mathrm{cm}$ ) and ultrapure concentrated $\mathrm{HClO}_{4}$ (Merck, suprapure) was used as electrolyte in all measurements.

Microscopy: Transmission electron microscopy measurements were performed at DTU Center for Electron Nanoscopy using an FEI Titan 80-300 ETEM electron microscope (STEM and TEM image) equipped with a monochromator and a spherical aberration corrector on the objective lens. A FEI Tecnai T20 G2 microscope was used for recording the TEM micrographs presented in the Supplementary Information. The microscopes were operated at $300 \mathrm{kV}$ accelerating voltage. Instrument conditions and acquisition parameters were kept constant within each specimen analysis. Despite receiving a higher energy dose during STEM analysis as compared to TEM analysis, we found that the Pt nanoclusters are stable under the electron beam long enough to obtain suitable images. Only upon extended irradiation the Pt clusters started to become mobile and we therefore focused and adjusted the electron beam in adjacent areas to the actual recorded STEM image. Obtaining atomic resolution was not possible due to the cluster mobility.

Micrograph analysis: Micrograph conversion to binary images and the particle analysis were done using the relevant functions of the ImageJ software. The threshold to define the black and white conversion was adjusted manually for each image by visual comparison between the original image and the processed image so that no artefact occurred in the conversion. For nanoparticle counts, the particles on corners and edges were excluded and a circularity of 0.1 was allowed. 
For each sample, between 3 and 7 different areas of the TEM grids were imaged in TEM and HAADF-STEM modes at different magnifications. An average value and standard deviation of the number of clusters per $\mathrm{nm}^{2}$ was obtained by averaging over the number of micrographs recorded for a given sample. For each sample, the total number of clusters over all micrographs

131 was evaluated. The distribution of clusters per $\mathrm{nm}^{2}$ as a function of the cluster areas (area 132 distribution functions, ADF) were obtained using the total number of clusters over all 133 micrographs taken for a given sample. The average area of clusters, the average diameter of

134 clusters and the related standard deviations as well as the fraction of the surface represented by 135 the clusters relative to the total surface analyzed were obtained using the total number of clusters 136 analyzed over all micrographs taken for a given sample. The cumulative probability representing 137 the cumulative nearest-neighbor distribution (NND) normalized to the average cluster diameter 138 (Ø) presented for illustration purposes were obtained from a single micrograph for a given 139 sample.

\section{RESULTS AND DISCUSSION}

141 Four different degradation mechanisms for Pt particles under electrochemical conditions are

142 classified [11], illustrated in Figure 1: particle migration and coalescence [12], metal (Pt) 143 dissolution [13], (electrochemical) Ostwald Ripening [14] and particle detachment [15]. To test 144 the hypothesis that small Pt clusters and nanoparticles are suitable for electrochemical 145 applications, we investigate the stability of extremely small, size selected Pt nanoclusters [8, 10, 146 16-19], which serve as a model system for more complex, industrial type PEMFC catalysts. The 147 Pt nanoclusters generated by a laser-ablation cluster source are deposited onto the amorphous 148 carbon film of transmission electron microscopy (TEM) grids, which can be used as a working 
electrode in electrochemical ADTs in a similar manner as in identical location TEM (IL-TEM) [20-22]. This approach allows for an independent control of the size and the density of the clusters, and the evaluation of how their properties vary in response to electrochemical ADTs (see also Supporting Information for an illustration of the flexibility in the design and preparation of our model catalysts).

In Figure 2, images and size distribution of a sample consisting of Pt nanoclusters made of 22 $\mathrm{Pt}$ atoms $\left(\mathrm{Pt}_{22}\right)$ are shown confirming that the $\mathrm{Pt}$ nanoclusters are in the subnanometer size-range. The first challenge for our approach was the selection of the most suitable analysis technique to identify the different degradation mechanisms. In the present study, we rely on a statistical analysis of the samples, contrary to our IL-TEM method, to identify the different degradation mechanisms. Therefore, we targeted to analyze at least $\mathrm{N}>500$ clusters per measurement via an automated particle counting and measuring routine. High-angle annular dark-field scanning transmission electron microscopy (HAADF-STEM) provides good contrast between substrate and Pt nanocluster suitable for the automated process (see comparison between the results from an automated HAADF-STEM and manual transmission electron microscopy (TEM) analysis in the Supporting Information). The highly homogeneous samples enabled us to analyze several different areas and thus to obtain the required statistical significance.

Several important parameters can be extracted from the STEM data: the density of clusters per surface area unit, the size distribution of the area covered by individual clusters, the average cluster diameter (calculated by assuming spherical clusters) and the nearest-neighbor distribution (NND) normalized to the average cluster diameter $(\varnothing)$. In Figure 2 for instance, a $\mathrm{Pt}_{22}$ sample is characterized by $0.059 \mathrm{Pt}_{22}$ clusters per $\mathrm{nm}^{2}$ with an average area covered by a single $\mathrm{Pt}_{22}$ cluster of $0.55 \pm 0.22 \mathrm{~nm}^{2}$ for an average cluster diameter of $0.82 \pm 0.15 \mathrm{~nm}$. The typical nearest- 
172 neighbor distribution (NND) between the Pt clusters for as-produced samples is plotted

173 normalized to the average diameter of the nanoclusters $(\varnothing)$ as well as in absolute distance. The

174 measured NND follows the theoretical curve assuming a random distribution, with a significance

175 calculated according to a Kolmogorov-Smirnov test using a statistical significance of $95 \%$ [16].

176 The difference between the experimental curve and the theoretical curve is reported as well. It is

177 observed that for NNDs smaller than 3.5 times the average cluster diameter, the experimental

178 results deviate from the random distribution. This can be explained by the sampling of the STEM

179 measurements: particles very close to each other (with a distance lower than ca. two times the

180 average cluster diameter) may be detected as a single large nanocluster. Cluster distances in the

181 range of one to three $\mathrm{NND} / \varnothing$ are therefore less likely detected.

182 Table 1. Properties before and after different electrochemical treatments (the square wave tests

183 were performed 3000 times prior to analysis) of representative $\mathrm{Pt}_{68}$ cluster samples prepared

184 using the same synthesis parameters.

\begin{tabular}{|l|c|c|c|c|}
\hline Treatment & $\begin{array}{c}\text { Clusters } \\
\text { per } \mathbf{~ n m}^{2}\end{array}$ & $\begin{array}{c}\text { Area } \\
\text { fraction of } \\
\mathbf{P t} \\
\text { nanoclusters } \\
{[\%]}\end{array}$ & $\begin{array}{c}\text { Average } \\
\text { diameter } \\
\text { of a } \\
\text { cluster } \\
\text { [nm] }\end{array}$ & $\begin{array}{c}\text { Number } \\
\text { of } \\
\text { clusters } \\
\text { analyzed }\end{array}$ \\
\hline Before test & $\begin{array}{c}0.028 \\
\pm 0.004\end{array}$ & 4.17 & $\begin{array}{c}1.27 \\
\pm 0.39\end{array}$ & 1638 \\
\hline $0.4 \mathrm{~V} / 3 \mathrm{~s}$ & $\begin{array}{c}0.031 \\
0.6 \mathrm{~V} / 3 \mathrm{~s}\end{array}$ & 4.35 & $\begin{array}{c} \pm .31 \\
\pm 0.34\end{array}$ & 1765 \\
\hline $0.4 \mathrm{~V} / 3 \mathrm{~s}$ & $\begin{array}{c}0.034 \\
0.8 \mathrm{~V} / 3 \mathrm{~s}\end{array}$ & 4.66 & 1.26 & 539 \\
\hline $0.4 \mathrm{~V} / 3 \mathrm{~s}$ & 0.023 & 3.54 & 1.40 & 1742 \\
$1.0 \mathrm{~V} / 3 \mathrm{~s}$ & \pm 0.005 & & & \\
\hline
\end{tabular}

185 
The high reproducibility of the cluster deposition as well as the independent control of nanoclusters' size and distribution directly on a TEM grid allows us to characterize the same cluster sample before and after electrochemical tests and to compare the influence of different ADTs in a systematic fashion [2]. To identify the respective degradation mechanisms, we analyzed the cluster diameter, cluster density and NNDs of the as prepared and degraded samples.

193 Figure 3 summarizes the results obtained for such electrochemical degradation tests

194 investigating $\mathrm{Pt}_{68}$ nanoclusters. This choice of cluster size was motivated by two factors. $\mathrm{Pt}_{68}$ nanoclusters are relatively large and therefore easy to identify on the grids. Further, they have an average diameter of around $1.1-1.3 \mathrm{~nm}$ (see Supporting Information), which is close to NPs used in fuel cells and/or obtained from other methods like wet chemistry. [23] The properties of the sample before and after electrochemical treatment together with the total number of clusters analyzed are summarized in Table $\mathbf{1 .}$

The as-prepared samples have a cluster density of $0.028( \pm 0.004)$ clusters per $\mathrm{nm}^{2}$ and an average cluster diameter of $1.27 \pm 0.39 \mathrm{~nm}$ is determined. The distribution of the clusters across the grid is random for all 7 micrographs analyzed. We then applied electrochemical tests consisting of potential steps starting from $0.4 \mathrm{~V}$ (all voltages are expressed vs. RHE) to $0.6 \mathrm{~V}$, $0.8 \mathrm{~V}$ and $1.0 \mathrm{~V}$. At each potential, the hold time was 3 seconds and 3000 cycles were applied. After stepping the potential between 0.4 and $0.6 \mathrm{~V}$, no significant change in the size distribution or cluster density is detected (cluster density of $0.031( \pm 0.001)$ clusters per $\mathrm{nm}^{2}$ and an average 207 cluster diameter of $1.31 \pm 0.34 \mathrm{~nm}$ for a step at $0.4 \mathrm{~V}$, cluster density of $0.034( \pm 0.001)$ clusters 208 per $\mathrm{nm}^{2}$ and an average cluster diameter of $1.26 \pm 0.43 \mathrm{~nm}$ for a step at $0.6 \mathrm{~V}$ ). However, the Pt nanoclusters are not randomly dispersed anymore (for all 6 micrographs analyzed), see Figure 3 . 
A NND between two to four $\varnothing$ is overrepresented as compared to what is expected from a random distribution. This indicates that the Pt nanoclusters become mobile under the applied electrochemical treatment and that they tend to arrange themselves at a distance of two to four times their average diameter. Electrochemically induced nanocluster migration at such mild conditions (room temperature) is quite surprising considering that in gas phase significantly higher temperatures are required to observe similar effects $[19,24,25]$. stays similar as just described. However, if the sample is subjected to potential steps between 0.4 $\mathrm{V}$ and $1.0 \mathrm{~V}$, the nanocluster density significantly decreases to a value of $0.023( \pm 0.005)$ clusters per $\mathrm{nm}^{2}$, whereas the average cluster diameter only slightly increases to $1.40( \pm 0.44) \mathrm{nm}$ (increase is within the experimental error). In addition, as in the previously discussed electrochemical tests, the NND/Ø distribution is not random anymore (in 6 different micrographs out of 7 analyzed) and the nanoclusters arrange themselves at a preferred distance of about two to four times the average cluster diameter.

224 Most standard electrochemical tests reach an upper value of around $1.0 \mathrm{~V}$ to be representative of realistic testing conditions in fuel cell applications (simulating PEMFC load cycles) [26]. 226 Migration of nanoparticles occurs on grids under electrochemical control when high voltages 227 (1.06 V are reached) [27]. It can be concluded from our experiments that even before reaching 228 oxidative potentials (i.e. below $1.0 \mathrm{~V}$ ) the distribution of clusters on the electrode undergoes a 229 significant modification. However, a significant decrease in catalytic surface area could not be 230 observed until $1.0 \mathrm{~V}$ is reached, Table 1 . When increasing the potential up to $1.0 \mathrm{~V}$ a loss in 231 terms of cluster detachment [20, 28] and/or minor Pt dissolution [7, 13] was observed in 232 agreement with previous reports. There is no indication of more complex mechanisms proposed 
in the literature, e.g. Ostwald ripening $[14,29]$ or coalescence [12], as they all would involve a more significant change in particle size distribution. Interestingly, for our $\mathrm{Pt}_{68}$ model system a preferred NND between the clusters is observed even at very mild ADT conditions (steps between $0.4-0.6 \mathrm{~V}$ ). The observation of this cluster rearrangement and an overrepresented distance of two to four times their average diameter suggests that even before the usual mechanisms connected to catalyst degradation can be identified, some surface modification and local migration of the clusters occur. The reason for this phenomenon is not clear at this point.

240 Possible explanations could be due to particle-particle interactions, but also local 241 inhomogeneities in the amorphous carbon layer. Unfortunately, the thin amorphous carbon film 242 of the TEM grid is difficult to assess by local spectroscopy, but in latter case the mobile clusters 243 could be trapped at specific sites of the carbon film. This hypothesis needs to be tested in future 244 investigations with different TEM grids allowing better control of the local carbon structure.

245 Our preparation method allows us to also test mixed Pt nanocluster samples. Such samples are 246 particularly interesting to further study the hypothesis of significant Pt dissolution and 247 concomitant Ostwald ripening. In Ostwald ripening larger nanoclusters grow at the expense of 248 smaller ones as has been observed in PEMFC degradation [3, 30]. Here, we prepared a sample of $249 \mathrm{Pt}_{68}$ nanoclusters and added $\mathrm{Pt}_{22}$ nanoclusters that should serve as a sacrificial $\mathrm{Pt}$ ion source to 250 promote Ostwald ripening. As demonstrated in Figure 4, the two cluster sizes deposited on the 251 same TEM grid can still be distinguished. As expected, the as-prepared sample shows a bi-modal 252 size distribution, matching the size of $\mathrm{Pt}_{22}$ and $\mathrm{Pt}_{68}$ nanoclusters. Applying an electrochemical 253 treatment consisting of a potential change between 0.4 and $1.0 \mathrm{~V}$ for 4 hours we did not observe 254 evidence of preferential dissolution of the smaller Pt clusters and/or Ostwald ripening. After the 255 electrochemical treatment, the two initial populations of $\mathrm{Pt}_{22}$ and $\mathrm{Pt}_{68}$ nanoclusters are still 
clearly distinguishable. This is in stark contrast to the expected behavior from Ostwald ripening. The Pt nanoclusters show a preferred inter-particle separation of ca. three to four times the average cluster diameter and the $\mathrm{NND} / \varnothing$ does not follow a random distribution anymore. The observed cluster migration therefore is not leading to significant agglomeration. These results suggest that the spatial-rearrangement of the nanoclusters upon electrochemical treatment can be a key factor preceding the commonly observed degradation routes in electrochemical devices using metal nanoparticles as catalyst.

\section{CONCLUSION}

In conclusion, we demonstrate that STEM investigation of size-selected Pt nanoclusters is a powerful tool for fundamental studies of catalyst degradation. The results demonstrate that even subnanometer Pt nanoclusters exhibit higher electrochemical stability than often assumed. In mild ADTs conditions, the main effect is particle migration without agglomeration. The possible trapping of Pt clusters at local inhomogeneities with increased cluster-support interaction could be an interesting concept for future investigations. At higher potential limits (in the typical operation range of PEMFCs) particle detachment and/or minor Pt dissolution is observed, but by

271 investigating mixed cluster samples it is clearly demonstrated that the smaller $\left(\mathrm{Pt}_{22}\right)$ do not 272 preferentially dissolve leading to Ostwald ripening. The results indicate that subnanometer Pt 273 clusters catalysts indeed might be a feasible option as extremely high-dispersed PEMFCs as long 274 as the operation conditions are carefully adjusted, and the active phase is effectively immobilized 275 onto the carbon support. 
Funding for presented work has been received from the Villum foundation (M.A.), the Danish sapere aude project (M.R., M.N., M.A.). U.H. and F.F.S. received financial support through DFG project He3454/23. J.Q. has received funding from the European Union's Horizon 2020 research and innovation program under the Marie Skłodowska-Curie grant agreement No 703366 (SELECTRON). We further acknowledge L. Kacenauskaite for Figure 1. J.Q and M.R contributed equally to this work.

\section{Notes}

The authors declare no competing financial interest.

\section{REFERENCES}

288 [1] R. Borup, J. Meyers, B. Pivovar, Y.S. Kim, R. Mukundan, N. Garland, D. Myers, M. Wilson, 289 F. Garzon, D. Wood, P. Zelenay, K. More, K. Stroh, T. Zawodzinski, J. Boncella, J.E. McGrath, M. Inaba, K. Miyatake, M. Hori, K. Ota, Z. Ogumi, S. Miyata, A. Nishikata, Z. Siroma, Y. Uchimoto, K. Yasuda, K.I. Kimijima, N. Iwashita, Scientific aspects of polymer electrolyte fuel cell durability and degradation, Chemical Reviews, 107 (2007) 3904-3951. Transactions, 41 (2011) 775-784. 
[4] U. Heiz, F. Vanolli, L. Trento, W.D. Schneider, Chemical reactivity of size-selected supported clusters: An experimental setup, Review of Scientific Instruments, 68 (1997) 19861994.

[5] A. Kongkanand, M.F. Mathias, The Priority and Challenge of High-Power Performance of (2016) 1127-1137.

[6] E. Antolini, Structural parameters of supported fuel cell catalysts: The effect of particle size, inter-particle distance and metal loading on catalytic activity and fuel cell performance, Applied Catalysis B-Environmental, 181 (2016) 298-313.

[7] L. Tang, B. Han, K. Persson, C. Friesen, T. He, K. Sieradzki, G. Ceder, Electrochemical

Stability of Nanometer-Scale Pt Particles in Acidic Environments, Journal of the American Chemical Society, 132 (2010) 596-600.

[8] T. Tsuzuki, Commercial scale production of inorganic nanoparticles, International Journal of Nanotechnology, 6 (2009) 567-578.

[9] S. Kunz, K. Hartl, M. Nesselberger, F.F. Schweinberger, G. Kwon, M. Hanzlik, K.J.J.

314 Mayrhofer, U. Heiz, M. Arenz, Size-selected clusters as heterogeneous model catalysts under applied reaction conditions, Physical Chemistry Chemical Physics, 12 (2010) 10288-10291.

316 [10] F.F. Schweinberger, M.J. Berr, M. Doeblinger, C. Wolff, K.E. Sanwald, A.S. Crampton, 317 C.J. Ridge, F. Jaeckel, J. Feldmann, M. Tschurl, U. Heiz, Cluster Size Effects in the 318 Photocatalytic Hydrogen Evolution Reaction, Journal of the American Chemical Society, 135 (2013) 13262-13265. 
[11] J.C. Meier, C. Galeano, I. Katsounaros, A.A. Topalov, A. Kostka, F. Schuth, K.J.J.

Mayrhofer, Degradation Mechanisms of Pt/C Fuel Cell Catalysts under Simulated Start-Stop Conditions, Acs Catalysis, 2 (2012) 832-843.

[12] C.G. Granqvist, R.A. Buhrman, Size Distributions for Supported Metal-Catalysts Coalescence Growth Versus Ostwald Ripening, Journal of Catalysis, 42 (1976) 477-479.

[13] S.G. Rinaldo, J. Stumper, M. Eikerling, Physical Theory of Platinum Nanoparticle Dissolution in Polymer Electrolyte Fuel Cells, Journal of Physical Chemistry C, 114 (2010) $5773-5785$.

[14] P. Wynblatt., N.A. Gjostein, Supported metal crystallites, Progress in Solid State Chemistry, 9 (1975) 21-58.

[15] K.J.J. Mayrhofer, J.C. Meier, S.J. Ashton, G.K.H. Wiberg, F. Kraus, M. Hanzlik, M. Arenz, Fuel cell catalyst degradation on the nanoscale, Electrochemistry Communications, 10 (2008) 1144-1147.

[16] M. Nesselberger, M. Roefzaad, R.F. Hamou, P.U. Biedermann, F.F. Schweinberger, S. Kunz, K. Schloegl, G.K.H. Wiberg, S. Ashton, U. Heiz, K.J.J. Mayrhofer, M. Arenz, The effect of particle proximity on the oxygen reduction rate of size-selected platinum clusters, Nature Materials, 12 (2013) 919-924.

[17] E.C. Tyo, S. Vajda, Catalysis by clusters with precise numbers of atoms, Nature Nanotechnology, 10 (2015) 577-588.

[18] V.P. Zhdanov, F.F. Schweinberger, U. Heiz, C. Langhammer, Ostwald ripening of supported Pt nanoclusters with initial size-selected distributions, Chemical Physics Letters, 631 (2015) 21-25. 
342

343

344

[19] K. Wettergren, F.F. Schweinberger, D. Deiana, C.J. Ridge, A.S. Crampton, M.D. Roetzer, T.W. Hansen, V.P. Zhdanov, U. Heiz, C. Langhammer, High Sintering Resistance of SizeSelected Platinum Cluster Catalysts by Suppressed Ostwald Ripening, Nano Letters, 14 (2014) 5803-5809.

[20] K.J.J. Mayrhofer, S.J. Ashton, J.C. Meier, G.K.H. Wiberg, M. Hanzlik, M. Arenz, Nondestructive transmission electron microscopy study of catalyst degradation under electrochemical treatment, Journal of Power Sources, 185 (2008) 734-739.

[21] A. Zana, J. Speder, M. Roefzaad, L. Altmann, M. Baumer, M. Arenz, Probing Degradation by IL-TEM: The Influence of Stress Test Conditions on the Degradation Mechanism, Journal of the Electrochemical Society, 160 (2013) F608-F615.

[22] J.C. Meier, I. Katsounaros, C. Galeano, H.J. Bongard, A.A. Topalov, A. Kostka, A. Karschin, F. Schuth, K.J.J. Mayrhofer, Stability investigations of electrocatalysts on the nanoscale, Energy \& Environmental Science, 5 (2012) 9319-9330.

[23] J. Speder, L. Altmann, M. Roefzaad, M. Baumer, J.J.K. Kirkensgaard, K. Mortensen, M. Arenz, Pt based PEMFC catalysts prepared from colloidal particle suspensions - a toolbox for model studies, Physical Chemistry Chemical Physics, 15 (2013) 3602-3608.

[24] T.W. Hansen, A.T. Delariva, S.R. Challa, A.K. Datye, Sintering of Catalytic Nanoparticles: Particle Migration or Ostwald Ripening?, Accounts of Chemical Research, 46 (2013) 1720-1730. [25] S.B. Simonsen, I. Chorkendorff, S. Dahl, M. Skoglundh, J. Sehested, S. Helveg, Direct Observations of Oxygen-induced Platinum Nanoparticle Ripening Studied by In Situ TEM, Journal of the American Chemical Society, 132 (2010) 7968-7975.

[26] A. Marcu, G. Toth, S. Kundu, L.C. Colmenares, R.J. Behm, Ex situ testing method to characterize cathode catalysts degradation under simulated start-up/shut-down conditions - A 
contribution to polymer electrolyte membrane fuel cell benchmarking, Journal of Power Sources, 215 (2012) 266-273.

[27] K. Hartl, M. Nesselberger, K.J.J. Mayrhofer, S. Kunz, F.F. Schweinberger, G. Kwon, M. Acta, 56 (2010) 810-816.

[28] K.J.J. Mayrhofer, D. Strmcnik, B.B. Blizanac, V. Stamenkovic, M. Arenz, N.M. Markovic, Measurement of oxygen reduction activities via the rotating disc electrode method: From Pt model surfaces to carbon-supported high surface area catalysts, Electrochimica Acta, 53 (2008) $373 \quad 3181-3188$.

374 [29] C.F. Yu, E.F. Holby, R.Z. Yang, M.F. Toney, D. Morgan, P. Strasser, Growth Trajectories 375 and Coarsening Mechanisms of Metal Nanoparticle Electrocatalysts, Chemcatchem, 4 (2012) $376 \quad 766-770$.

[30] N. Hodnik, M. Zorko, B. Jozinovic, M. Bele, G. Drazic, S. Hocevar, M. Gaberscek, Severe accelerated degradation of PEMFC platinum catalyst: A thin film IL-SEM study, Electrochemistry Communications, 30 (2013) 75-78.

\section{APPENDIX}


1. Migration and Coalescence

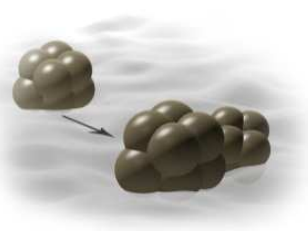

2. Metal Dissolution

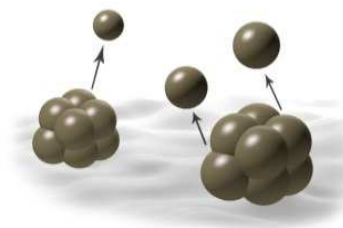

3. Ostwald Ripening

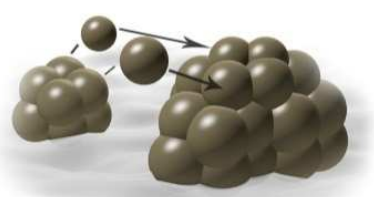

4. Particle Detachment

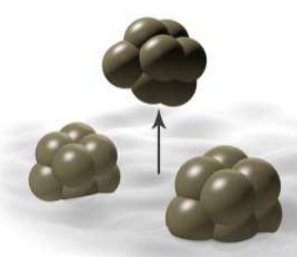

389

390

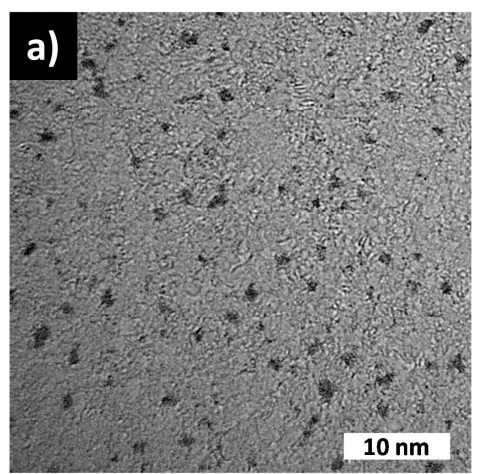

d)

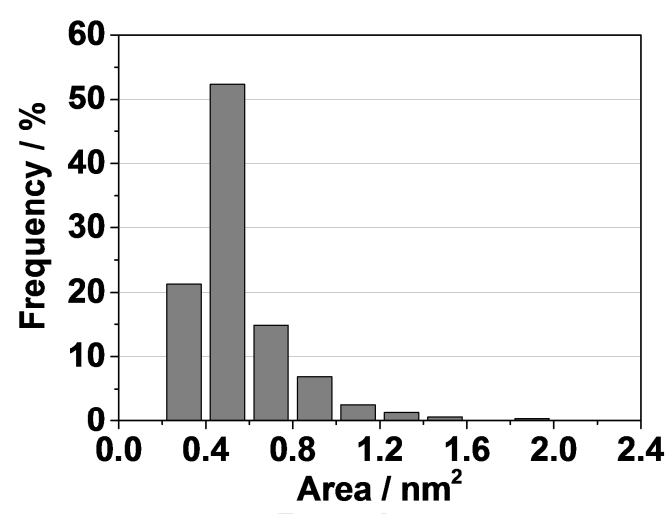
and nanoparticles under electrochemical ADTs.
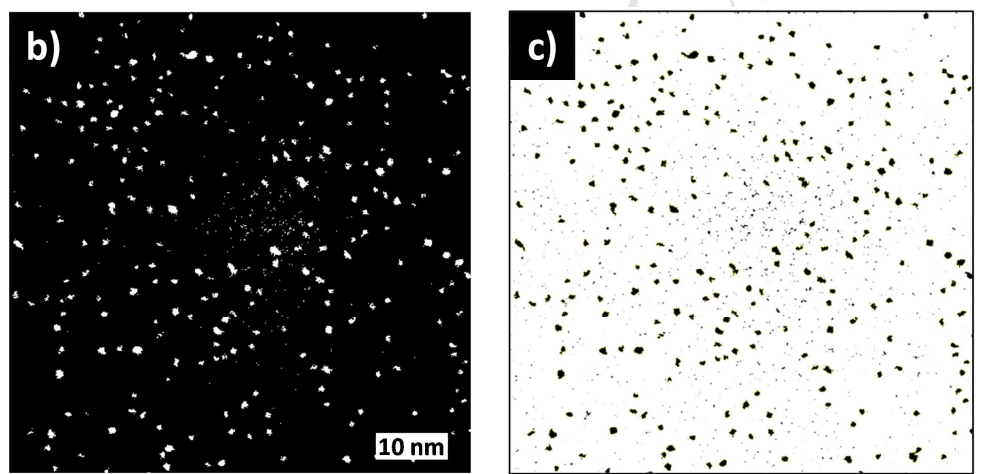

e)

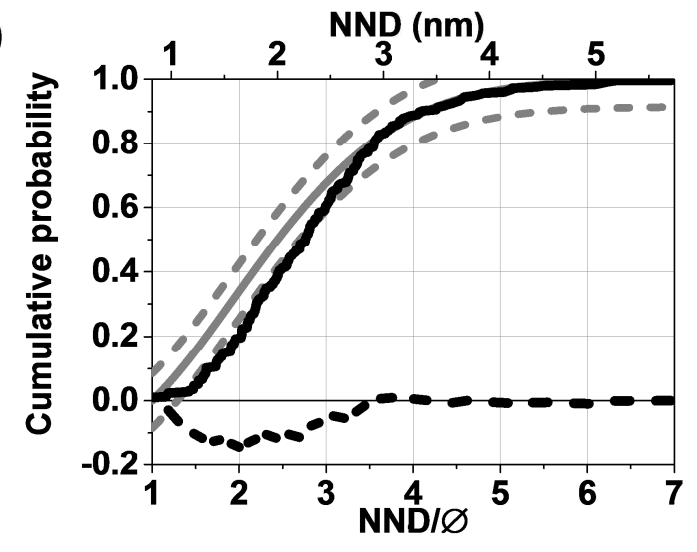

Figure 1. Schematic representation of the various degradation mechanisms of metal nanoclusters

393

Figure 2. Characterisation of the TEM grids covered with size-selected Pt clusters consisting of exactly 22 atoms $\left(\mathrm{Pt}_{22}\right)$. (a) TEM and (b) HAADF-STEM micrograph of a cluster sample with a coverage of $0.059 \pm 0.000$ (3) $\mathrm{Pt}_{22}$ clusters per $\mathrm{nm}^{2}$ (estimated from the analysis of 3 different micrographs). (c) HAADF-STEM micrograph converted to a binary black-and white image. (d) Area distribution function (ADF) of Pt clusters presented as histogram retrieved from the analysis of 741 clusters. (e) Cumulative nearest-neighbour distribution (NND) normalized to the 
399

400

401

402

403

404

average cluster diameter $(\varnothing)$ of the nanoclusters (black solid line), theoretical curve assuming a random distribution (grey solid line), significance calculated according to a KolmogorovSmirnov test using a statistical significance of $95 \%$ (in-between the two dashed grey curves). The difference between the experimental data (black solid line) and the theoretical data assuming a random distribution (grey solid line) is indicated by the dashed black line.

405
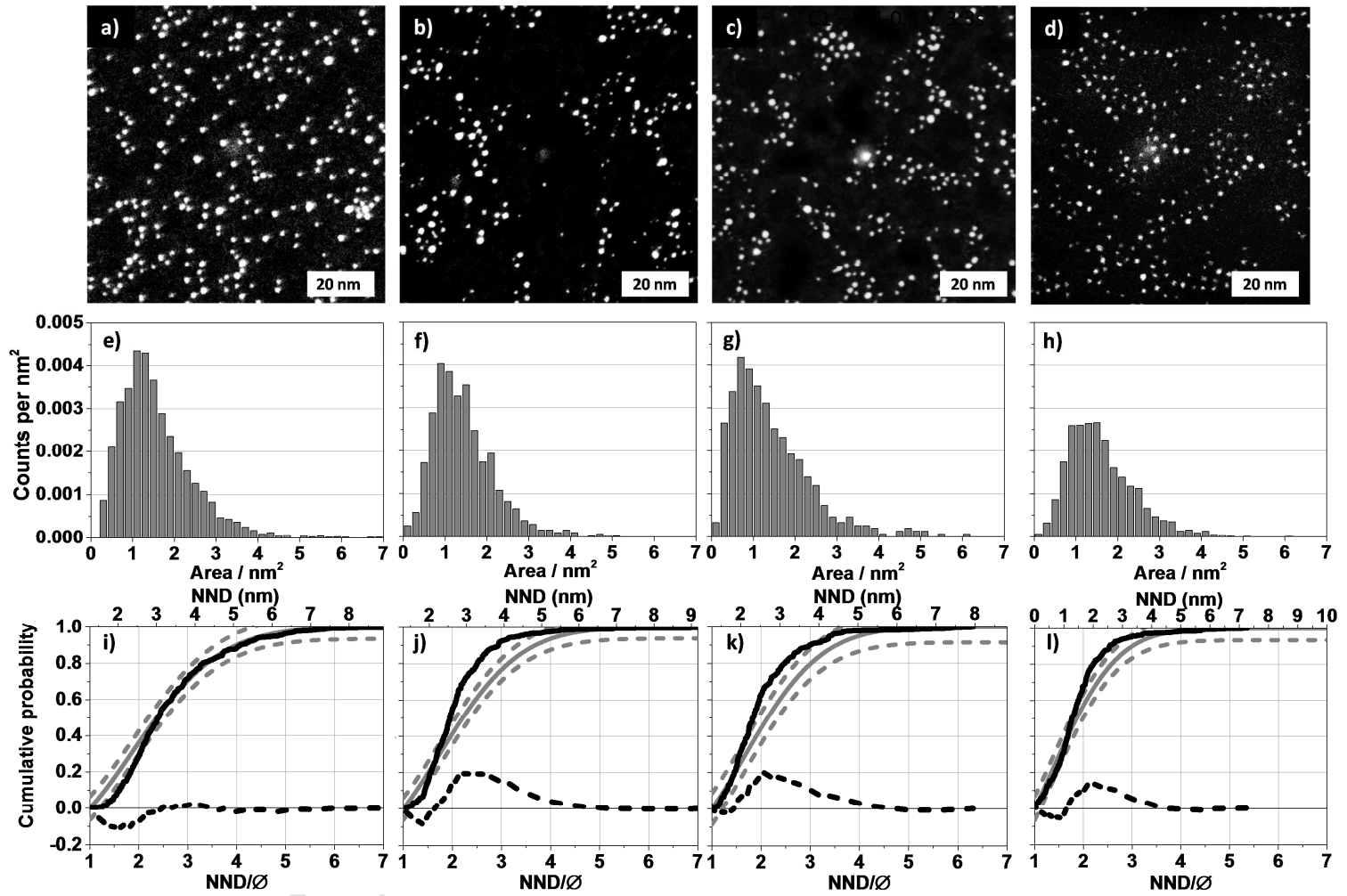

Figure 3. (a-d) HAADF-STEM micrographs of $\mathrm{Pt}_{68}$ nanoclusters, (e-h) distributions of the area covered by a single cluster, (i-l) graphs representing the cumulative nearest-neighbour distribution (NND) normalized to the average diameter $(\varnothing)$ of the nanoclusters (black solid line), the theoretical curve assuming a random distribution (grey solid line), the significance calculated according to a Kolmogorov-Smirnov test using a statistical significance of $95 \%$ (area between 
411 the two dashed grey lines) and the difference between the experimental and the theoretical data 412 assuming a random distribution (black dashed line). Conditions: (a,e,i) before electrochemical 413 testing; $(\mathrm{b}, \mathrm{f}, \mathrm{j})$ after a potential change from $0.4 \mathrm{~V}$ for 3 seconds to $0.6 \mathrm{~V}$ for 3 seconds; (c,g,k)

414 after potential change from $0.4 \mathrm{~V}$ for 3 seconds to $0.8 \mathrm{~V}$ for 3 seconds; $(\mathrm{d}, \mathrm{h}, \mathrm{l})$ after a potential 415 change from $0.4 \mathrm{~V}$ for 3 seconds to $1.0 \mathrm{~V}$ for 3 seconds. The square wave test was performed 4163000 times prior to analysis. The analysis results are summarized in Table 1.

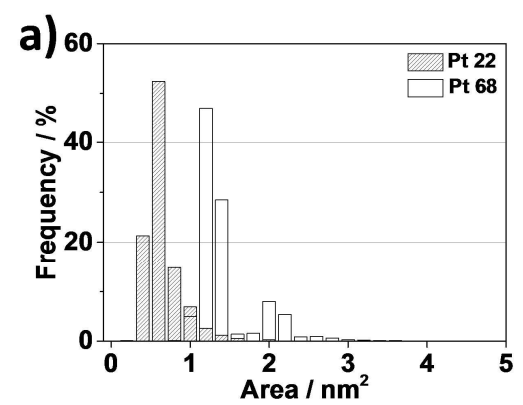

b)
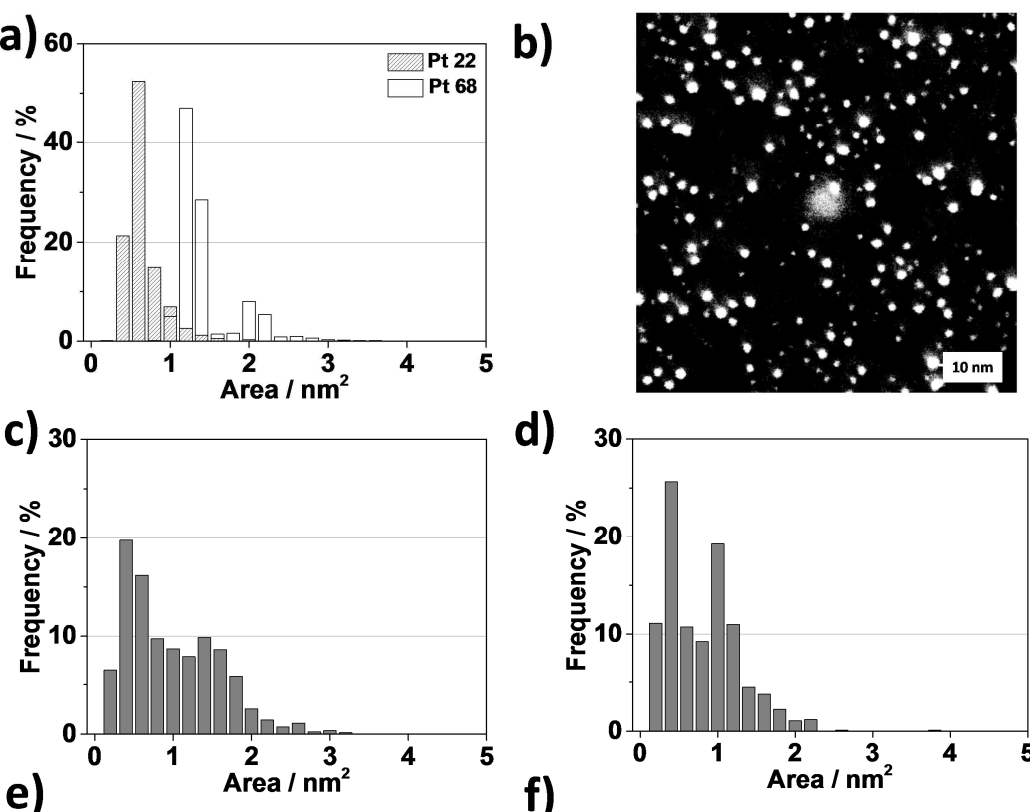

d)
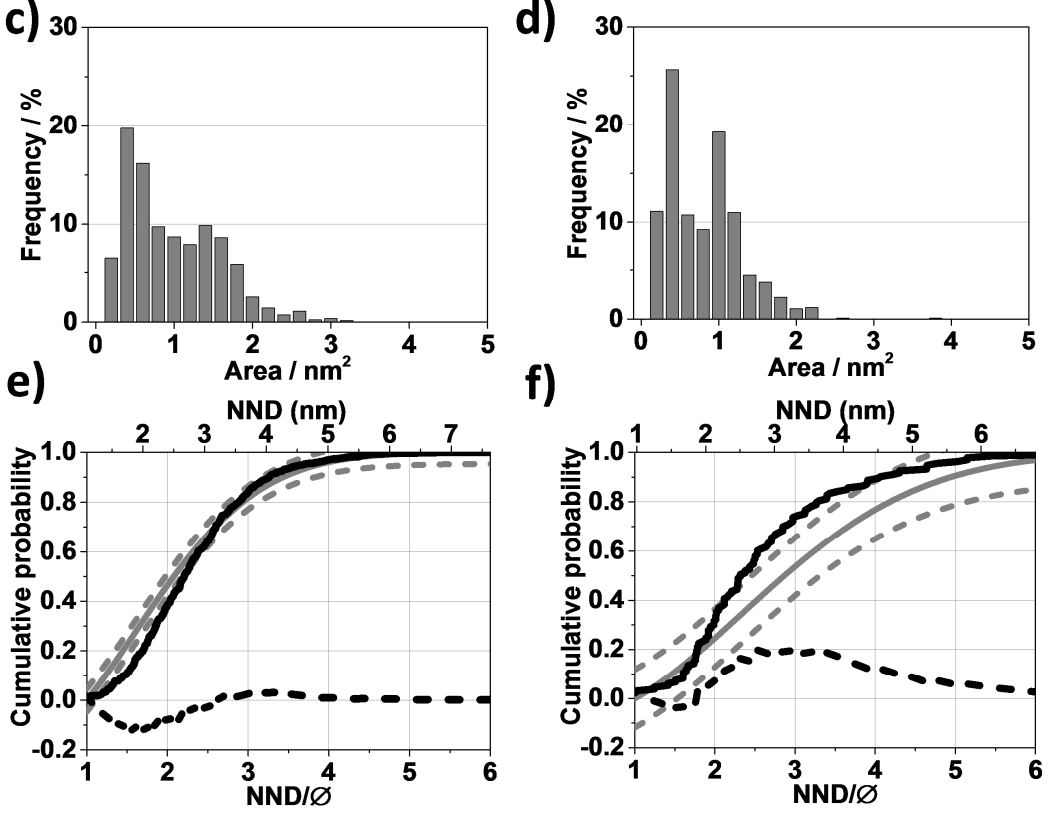

419 Figure 4. (a) Area distribution functions (ADF) of two separate cluster samples with $\mathrm{Pt}_{22}$ and $420 \mathrm{Pt}_{68}$ nanoclusters. 741 clusters for $\mathrm{Pt}_{22}$ and 1143 clusters for $\mathrm{Pt}_{68}$ were analyzed as detailed in

Table S2. (b) Representative HAADF-STEM micrograph of the mixed cluster sample with $\mathrm{Pt}_{22}$ 
and $\mathrm{Pt}_{68}$ nanoclusters co-deposited on the same TEM grid. (c,d) ADF of mixed cluster sample (c) before electrochemical testing and (d) after potential steps from $0.4 \mathrm{~V}$ to $1.0 \mathrm{~V}$ for 1 and 3 seconds hold times. The square wave test was performed for 4 hours. (e,f) Graphs representing the cumulative nearest-neighbor distribution (NND) normalized to the average cluster diameter (Ø) (black solid line), the theoretical curve assuming a random distribution (grey solid line), the significance calculated according to a Kolmogorov-Smirnov test using a statistical significance of $95 \%$ (area between the two dashed grey curves) and the difference between the experimental and theoretical data assuming a random distribution (dashed black curve). Conditions: (e) before electrochemical testing; (f) after square wave test.

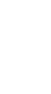

